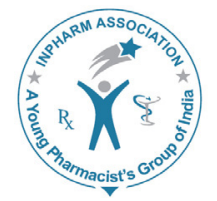

\title{
Viewpoints from an Educational Workshop of the AIMST University
}

Sir,

In Asia, the education industry of Malaysia is performing well in the education arena. Based on existing strength, Malaysia does have a potential to become region's education hub. Currently, Malaysia is able to attract number of foreign students from various countries. However, foreign student's number is likely to grow rapidly in the near future. Currently, there are more than 62 Higher Education Institutions (HEIs) in the country (including satellite branches of the foreign universities) that offers biomedical degree programmes. Due to high competition, all HEIs are on their toes to maintain and or to improve the educational quality. In fact, in order to grow further, each HEI in Malaysia is putting-in-efforts to enhance the quality of their various biomedical and non-biomedical degree programmes by ensuring that the courses remains affordable for local as well as foreign students.

The AIMST University (AIMST) is the first private and notfor-profit university in the northern part of the Peninsular Malaysia that offers various biomedical and non-biomedical degree programmes. Currently, AIMST receives about 53$57 \%$ extra applications (apart from the quota given by the

\begin{tabular}{|c|c|}
\hline \multicolumn{2}{|c|}{ Access this article online } \\
\hline Journal Sponsor & \multirow[b]{2}{*}{$\begin{array}{l}\text { Website: } \\
\text { www.jyoungpharm.org }\end{array}$} \\
\hline \multirow{2}{*}{ www.phcog net } & \\
\hline & $\begin{array}{l}\text { DOI: } \\
\text { 10.5530/jyp.2015.1.9 }\end{array}$ \\
\hline
\end{tabular}

Ministry of Education) from students for the admission in biomedical degree programmes. The extra number of applications for biomedical degree programmes also indicates the student's preference for biomedical degree programmes over non-biomedical programmes. Currently, student's first, second and third preference is for 'Bachelor of Medicine, Bachelor of Surgery (MBBS)', 'Bachelor of Dental Surgery (BDS)', and 'Bachelor of Pharmacy (BPharm)', respectively. However, biotechnology degree programmes are also becoming popular among the students.

To develop and enhance the capacity of potential' and existing 'academic staff-in-leadership-role', AIMST does conduct the workshops called 'University Leadership Camps (ULCs)' on a regular basis. A summary of recently held sixth ULC (ULC-VI) is reported in this article.

In the education industry, the number of HEIs are growing continuously especially in the countries where education sector is open for the foreign HEIs; hence, the competition of attracting students is becoming fierce. In this line, in the opening talk, speaker highlighted that for the sustainability of various biomedical and non-biomedical higher education degree programmes, each university need to leverage on the innovation as a new engine of growth. To demystify the message, the innovative approaches used by Apple Inc., TESCO [a British multinational grocery and general merchandise retailer], and DELL Inc. were discussed.

The needs of the industry, and needs and wants of new

\section{*Address for correspondence:}

Dr. Subhash J. Bhore, Department of Biotechnology, Faculty of Applied Sciences, AIMST University, Bedong-Semeling Road, 08100 Bedong, Kedah, Malaysia,E-mail: subhashbhore@gmail.com /subhash@aimst.edu.my 
generation of students are pushing for the innovation in the academic programmes. Therefore, academic staff-in-leadershiprole needs to adapt relevant changes in time in programme curriculum in line with the needs of students and demand of industry. Speaker deliberated that academic staff-in-leadershiprole always needs to ask five questions - What is changing? Where are the gaps? How can we change the status quo? How can we learn from others? And, where are our own gaps? As a result, academic staff-in-leadership-role can identify the changes that need to be done, and the relevant changes with innovation can be incorporated in the biomedical and nonbiomedical higher degree programmes of the university.

While debating about managing talent and performance, speaker highlighted that in the process of biomedical and non-biomedical curriculum development, doing innovative changes in it as a part of continual quality improvement, academic teaching, research and administration, the role and approach of academic staff-in-leadership-role is very important. Therefore, academic staff-in-leadership-role should be able to manage the talent prudently. In this line, Deans, Deputy Deans, Acting Deans, and Heads of each School, Department, Units and Divisions should have the managerial skills. Academic staff-in-leadership-role always needs to set the targets for better productivity preferably without swelling cost. However, to get the best from the staff, both non-academic and academic staff-in-leadership-role should not forget the humane factor while dealing with staff.

The engagement and a real involvement of all staff (academic and non-academic) of the university is essential in order to achieve the common goals of the respective units, sections, divisions, departments, faculties, and the whole university. In this line, the importance of ongoing 'short-term', 'mid-term' and 'long-term' engagement of both academic and non-academic staff was highlighted. If the faculty of the university is really committed and engaged then achieving the common goals becomes relatively easy, and it can have a 'huge positive impact' on the quality of the academic programmes and brand of the university. In the university organization, workshops such as 'ULC' helps in bringing all the 'potential' and 'existing staff-in-leadership-role' together to bring them on the same page. However, programmes or gatherings for instance, 'meet the staff [academic and non-academic staff of the university] sessions' helps in bringing all staff of the university together to share the achievements and challenges of the university. It can be implemented at both faculty level and university level. Based on the current practices of the AIMST, we are proposing the 'People Engagement Model (PEM)' for the HEI as depicted in the Figure 1. In this model, short-term is for premium

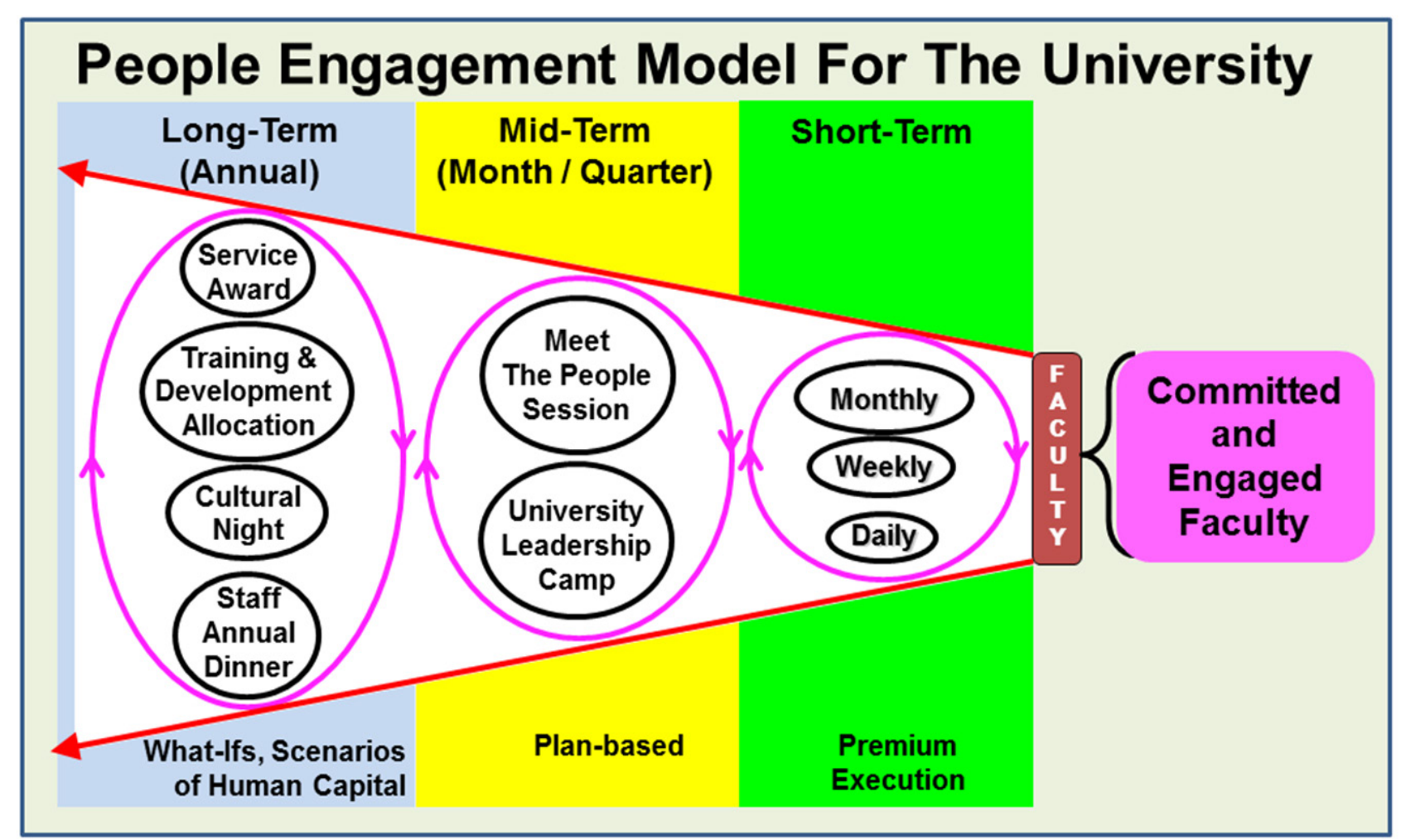

Figure 1: The proposed 'People Engagement Model (PEM)' for the higher education institutions (HEIs) based on the practices adopted by AIMST University; the term 'people' denotes the 'academic and non-academic staff' of the HEI. 


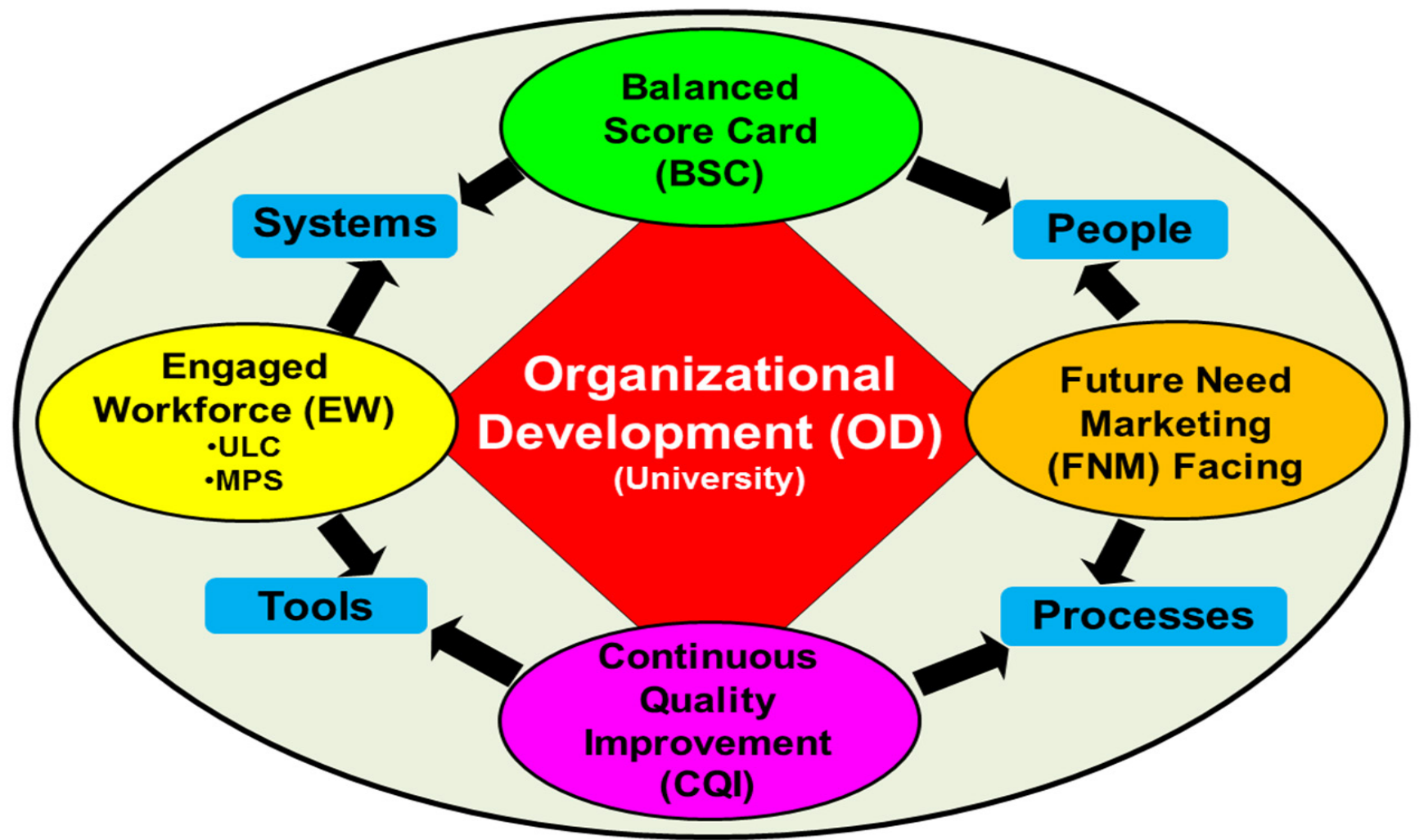

Figure 2: The proposed 'Organizational Development Model (ODM)' for the higher education institutions (HEls) based on the practices adopted by AIMST University. ULC, university leadership camp; MPS, meet the people session; the term 'people' denotes the 'academic and non-academic staff' of the HEI.

execution; whereas, mid-term and long-term engagement activities are plan-based and to address the 'what-ifs scenarios of the human capital', respectively.

In this modern world, HEIs need to function like corporate organizations. To do so, HEIs need to adopt and adapt with the best known methods (BKM) practiced. In this line, AIMST has adopted the Balanced Score Card (BSC), a system that enables the close-monitoring of the goals and performance. The BSC matrix helps in setting the goals for each year or academic year and it's monitoring throughout the year at Unit, Division, Department, Faculty and University level. Actually, AIMST is the first in Malaysia to implement the BSC successfully.

While talking about the organizational (university) development, speaker highlighted that engaged workforce (EW), BSC, continual quality improvement (CQI) and future need marketing (FNM) are the major four domains that helps in organizational development. In addition to this, the efficient and effective use of EW, BSC, CQI, and FNM can help in achieving the goals of the organization. Based on the current practices adopted by AIMST, we are proposing the 'Organizational Development Model (ODM)' as illustrated in Figure 2. We strongly believe that if this model is implemented systematically then it must help respective HEI in its organizational development.

While talking about enhancing the performance of the employees, speaker highlighted that the employees can make the wonders if academic staff-in-leadership-roles [Heads of individual Unit, Division, Department, Faculty and or Centers] are effective and efficient in managing employee's talent and performance. To clarify this message, 'managing talent and performance', a case study from Stanford University was debated. To get the best out of engaged and committed staff, academic staff-in-leadership-roles should be efficient and effective in planning, execution and 
evaluation (honest appraisal), speaker highlighted. academic staff-in-leadership-roles who are very effective at development of their staff can outperform their peers by up to $25 \%$. Therefore, academic staff-in-leadership-roles should be effective in developing their staff.

The quality of all academic staff and their collective productivity determines the output and achievements of the respective HEIs. In this context, the importance of teaching and research quality was debated while discussing about world class universities and world class education. At the end of the deliberation, all participants were of a view that we should not neglect quality of the teaching. However, all participants were made aware of the fact that we cannot preclude the importance of the research and its necessity. 'Teaching', 'research', 'knowledge transfer', and 'international outlook of the HEIs' were highlighted as the essential attributes for becoming a world class HEI. The three key factors namely, 'an excellent pool of talent', 'abundant resources', and 'favorable governance' were highlighted as the typical features of the world class university.

Education industry is changing rapidly, and in this context the 'access to knowledge', 'advances in digital technologies', 'integration of industry', 'global mobility', and 'contestability of market' were highlighted as the real drivers of change for the HEIs. Due to increasing number of HEIs and steep competition, market share of most of HEIs is shrinking. Therefore, academic staff-in-leadership-role needs to understand driving forces, its impact on the own faculty, HEI and the remedial roles.

Like other HEIs, AIMST do have a plan for internationalization, and in this context the staff-in-leadershiprole were made aware of the importance of-generating knowledge in collaboration with international (and national) partners, recruiting international talent at all levels, training students to have international competency, and having footprints at international level within education, research and technology transfer domains. Strategic alliances, visibility and branding of the HEI were highlighted as the prerequisites for the HEI's internationalization. Whereas, for the internationalization of the education, 'more subjects availability' and 'completeness of degree programmes aligned to international standards', 'creating more flexibility in the degree programmes', 'establishment of an international students need based programmes', 'increase in international collaboration' for the content development and planning of the degree programmes, and 'increase in use of international quality standards' is essential, participants learned.
For each HEI, the internationalization of the research is very essential in order to enhance the visibility and to build the reputation. In this context, the importance of developing more research projects with international collaborators, increasing international research funding, and publishing research findings in high impact factor (IF) journals was highlighted. In addition to this, mobility of both, the students and staff is important in the process of internationalization. In this line, academic staff-in-leadershiproles were made aware of the importance of - recruiting professional foreign talent for research, developing support system for incoming and outgoing researchers and promotion of outgoing mobility of researchers under exchange programmes.

As a part of each HEI's internationalization efforts, it is important to establish and further develop the strategic alliances with strong HEIs from abroad. In this context, academic staff-in-leadership-roles were encouraged to focus on collaboration with elite universities and to involve in key university networks to support in achieving the university's overall goals.

If the Asian HEIs establishes the strategic alliances successfully with their strong counterparts from abroad then there is a great potential in offering 'Dual Degree' (also referred as 'Double Degree') or 'Joint Degree' programmes. Both, 'Dual Degree' and 'Joint Degree' can be offered in both biomedical and non-biomedical academic programmes. Students will benefit from this type of arrangements and academic staff-in-leadership-roles were urged to take the initiatives.

In an interactive session, speaker highlighted that organizing high-profile conferences with international participation, and representation by our academic staff and students in key international scientific forums is important for the overall growth and development of the staff and students. However, at the same time these activities greatly contribute in enhancing the visibility and branding of the university/ HEI. In HEIs, every faculty and or department should take initiatives in organizing international conferences and prefer to present research findings in the international scientific forums.

In the final session, speaker highlighted that student's voice is important and academic staff need to focus on enhancing student's learning and not just student's satisfaction. All the programmes should be student-centric, and the ultimate aim should be to develop the best experts and citizens for tomorrow. Students of the HEIs are the best ambassador for their respective HEIs, and it should be reflected in their 
depth of knowledge, global thinking, innovativeness and overall behavior, speaker highlighted.

In a nutshell, the 'ODM' and 'PEM' proposed in this report and practiced at AIMST represent a new version of models for organizational development and employee engagement in university operation. These models could be useful for other HEIs in improving the effectiveness of 'organizational development' and 'employee engagement'. Nevertheless, insights on university's internationalization and other issues highlighted in this report may be useful to academicians, university administrators, policy makers, and staff-in-leadership-role in other HEIs.

\section{ACKNOWLEDGMENTS}

The authors gratefully acknowledge that this workshop [University Leadership Camp (VI)] was fully supported by the AIMST University, Malaysia. The authors also wish to record special thanks to the dedicated 'Supporting Team of the AIMST University' for organizing this workshop.

\section{CONFLICT OF INTERESTS}

The authors declare that there is no conflict of interests regarding the publication of this paper.

\section{Rajagopal Premkumar ${ }^{1}$, Subhash Janardhan Bhore ${ }^{2, *}$}

${ }^{1}$ Chancellery, AIMST University, Bedong 08100, Kedah, Malaysia

${ }^{2}$ Department of Biotechnology, Faculty of Applied Sciences, AIMST University, Bedong-Semeling Road, Semeling 08100,

Kedah, Malaysia 